\title{
El inicio de la guerra civil y sus repercusiones en los diplomáticos españoles acreditados ante el Quirinal y el Vaticano
}

\author{
marina Casanova
}

Desde el inicio de la guerra civil española el 18 de julio de 1936 hasta el nombramiento de Francisco Largo Caballero como presidente del Consejo de Ministros trascurrieron dos meses de incertidumbre y de indecisiones por lo que se refiere a la actitud de los diplomáticos españoles.

En todas las representaciones españolas en el extranjero se recibieron dos comunicaciones, un telegrama de la Junta de Defensa Nacional, y una Circular del ministro de Estado del Gobierno de la República, Augusto Barcia. En el primero, la Junta de Defensa, dudando de la fidelidad de los embajadores ante el alzamiento por haber sido nombrados por el Gobierno republicano, acordaba su inmediata destitución y les ordenaba entregar el control de la embajada al secretario de la misma. Por otro lado, encargaba al encargado de Negocios comunicase al Ministerio de Asuntos Exteriores correspondiente, la formación y toma de poder del nuevo Gobierno constituido el 23 de julio de $1936^{1}$.

La Circular 23 del Ministerio de Estado requería a todos los diplomáticos con los que podía contar incondicionalmente, de enviar un telegrama al titular del Ministerio haciendo saber en su nombre, y en el del

1 El telegrama estaba firmado por el presidente de la Junta, general Miguel Cabanellas; general Andrés Saliquet; general Miguel Ponte; general Emilio Mola; general Fidel Dávila; coronel Federico Montaner y coronel Fernando Moreno. 
personal a sus órdenes, quiénes se encontraban plenamente identificados con el régimen y el Gobierno republicano.

Manuel Aguirre de Cárcer había sido nombrado embajador de España ante el Quirinal pocos meses antes del inicio de la guerra civil y acababa de llegar a Roma cuando tuvo lugar la sublevación. Aguirre de Cárcer envió el telegrama de adhesión al Gobierno republicano el 22 de julio. Durante los acontecimientos que se produjeron en días sucesivos no están muy claros los motivos que llevaron al embajador español a cambiar su decisión. Por un lado, el 26 de julio envió un nuevo telegrama al ministro de Estado en el que puntualizaba que «desde el momento en que la Circular del 23 de julio había igualado los conceptos de régimen y Gobierno, y pedía a los funcionarios diplomáticos no solamente fidelidad a la República, sino que se adscribiesen a una política interna determinada, a un partido, en su caso se veía imposibilitado a hacerlo sin violentar su conciencia». En su opinión, las recientes actuaciones gubernativas habían conducido a desnaturalizar el perfil del régimen mismo ${ }^{2}$.

Sin embargo, en un informe del embajador francés al ministro Delbos, le comunicaba que según el ministro de Asuntos Exteriores italiano, la actuación de Aguirre de Cárcer estuvo motivada por la violenta intervención de los Agregados Militar y Naval, completamente identificados con la sublevación, obligándole a renunciar a la presentación de Cartas Credenciales la víspera del día fijada para tal acto ${ }^{3}$.

En efecto, el 27 de julio, Aguirre de Cárcer envió un nuevo telegrama al ministro Barcia comunicándole que los agregados Militar y Naval habían difundido por radio su adhesión a la Junta de Defensa y le habian prohibido la entrada en la cancillería, negándose a abandonarla hasta que no se hubiese publicado su dimisión en el Diario Oficial ${ }^{4}$. Ese mismo día se recibió un telegrama en la Embajada de Roma comunicando al agregado Militar, señor Villegas, y al agregado Naval, señor Estrada, su baja en el Ejército en virtud de una Orden de los ministros de Guerra y Marina.

El 28 de julio, el ministro Barcia responde a Aguirre de Cárcer y considera que su posición moral y sus manifestaciones son sinceras, confirmándole como embajador y dejando a ulteriores consideraciones del problema planteado para un momento más oportuno. Al mismo tiem-

\footnotetext{
AMAE. RE. 163-164.

${ }^{3}$ AMAEF, Europe, 1930-1940. Espagne, V. 140, 10-8-1936.

4 AMAE. RE. 163-164.
} 
po, Barcia le comunica que el cónsul español en Roma, Pelayo García Olay, seguía mereciendo la confianza del Gobierno republicano ${ }^{5}$.

A pesar de todo, el mismo 28 de julio, Aguirre de Cárcer comunicó al ministro de Estado su irrevocable dimisión. La actitud del embajador español crearía un caso particular en las actuaciones llevadas a cabo por el Gobierno franquista en relación con los diplomáticos. El Decreto Ley de 11 de enero de 1937, reorganizó la carrera diplomática por parte del Gobierno de Franco, creándose una nueva formada exclusivamente por aquellos funcionarios que hubieran demostrado su leal adhesión a la "causa de España" ${ }^{6}$.

El caso de Aguirre de Cárcer fue considerado especial por los Tribunales de Depuración de funcionarios diplomáticos. Reclamado por el capitán juez instructor, Miguel Ferrer Álvarez en el Juzgado Militar, número 4, de Salamanca, en la causa que se le instruía se declaraba que Manuel Aguirre de Cárcer se encontraba ausente y en paradero desconocido, y que había sido declarado en rebeldía con arreglo al Código de Justicia Militar. En consecuencia, no se consideró pertinente practicar ninguna diligencia hasta su presentación o captura ${ }^{7}$. Nueve años después de su dimisión como embajador en Roma, y tras un largo proceso por parte del Tribunal de Revisión de funcionarios diplomáticos, Manuel Aguirre de Cárcer fue reincorporado al servicio activo en el Ministerio de Asuntos Exteriores el 12 de septiembre de $1945^{\circ}$.

Como consecuencia de la dimisión de Aguirre de Cárcer, correspondía al ministro consejero, García Olay hacerse cargo de la cancilleria. Sin embargo, según declaraciones del Conde Ciano, el joven diplomático hizo saber al Palacio Chigi que se encontraba demasiado enfermo para llevar a cabo las funciones de encargado de Negocios ${ }^{9}$. El ministro Barcia nombró entonces el 30 de julio como encargado de Negocios a José María Aguinaga y Barona que se encontraba en Berna al frente de la

5 AMAE. RE. 163-164.

"Casanova, Marina, "Depuración de funcionarios diplomáticos durante la guerra civil»", en Espacio, Tiempo y Forma. Madrid, UNED, 1987, pág. 361.

7 AMAE. Fondo Navasques, mayo 1938.

${ }^{8}$ AMAE. Escalafón Cuerpo Diplomático, 31-1-1946.

9 AMAEF. Europe, 1930-1940. Espagne, V. 140. Roma, 10-8-1936.

AMAE. FN. García Olay fue uno de los primeros diplomáticos españoles en mandar su adhesión a la Junta de Defensa. Cuando llegó a Roma el primer representante oficioso franquista, marqués de Magaz, García Olay se puso a su disposición. Posteriormente, regresó a España, y después de estar algún tiempo en Burgos y Salamanca, se siguió contra él un sumario del que fue absuelto en Consejo de Guerra celebrado en Salamanca y admitido en la nueva carrera diplomática franquista. 
legación española. Cuando llegó a Roma se encontró con grandes dificultades, debido sobre todo, a sus compañeros de embajada y a los miembros de la colonia española, en su mayoría favorables a los rebeldes. Inicialmente, Aguinaga se instaló en el consulado de España y posteriormente en los locales del Palacio Barberini, gracias a la "dudosa" intervención del ministro de Asuntos Exteriores italiano ${ }^{10}$. En efecto, el señor Aguinaga fue recibido el 3 de agosto por el Conde Ciano, quien se interesó sobre su situación en la cancillería. Aguinaga mantuvo su inquebrantable proposito y derecho de establecerse como representante de España, cerca de un país amigo en los locales de la embajada donde se encontraban la cifra y documentos. Sin embargo, los locales se hallaban ocupados por el personal insubordinado que no estaba dispuesto a abandonarlos, dejándole en una situación incompatible con la dignidad de su misión. Por otro lado, el Conde Ciano habia afirmado que la solicitud del ministro Barcia para la acreditación de Aguinaga no habia seguido los requerimientos habituales para tales casos. La actitud del ministro de Asuntos Exteriores estaba motivada, evidentemente, por motivos de carácter ideológico, pero disfrazados de un tono humanitario al inquietarse sobre la repercusión que la guerra civil podría tener sobre los súbditos italianos residentes en España ${ }^{11}$.

Una de las primeras manifestaciones del encargado de Negocios español fue la publicación, en nombre del ministro Barcia, de un desmentido sobre las declaraciones que, presuntamente, había realizado el ministro a un representante del Intransigente relativas a las pretensiones italianas sobre Ceuta y Mahón, como recompensa por su apoyo prestado a los rebeldes ${ }^{12}$. En realidad, las relaciones entre el Gobierno italiano y el Gobierno español no podian ser más tensas a la vez que engañosas. Para el Gobierno republicano era de sobra conocida la actitud y ayuda prestada por el Gobierno de Mussolini a los rebeldes.

En efecto, la primera petición de ayuda por parte de los rebeldes al Gobierno italiano fue requerida por Franco, quien envió a Luis Bolín a Roma para soliticar 12 bombardeos y tres cazas. Sin embargo, Franco no gozaba por aquel entonces de prestigio internacional en las capitales extranjeras. Por otro lado, cinco días después de la sublevación, Roma

10 AMAEF. Europe, 1930-1940. Espagne, V. 140. Embajador francés a ministro Delbos. Roma, 14-8-1936.

AMAE. RE. 163. Roma, 3-8-1936.

12 AMAEF. Europe, 1930-1940, V. 140, 10-8-1936. 
no sabia con exactitud lo que estaba sucediendo en España. La respuesta de Mussolini fue negativa ${ }^{13}$.

Sin embargo, gracias a la intervención del marqués de Viana, amigo personal de Alfonso XIII, Bolín fue recibido por el Conde Ciano, quien le prometió la ayuda solicitada. No obstante, no queriendo contradecir la decisión inicial de su suegro, cambió de idea y se negó a recibirle de nuevo ${ }^{14}$. En opinión de numerosos historiadores, la intervención italiana fue finaimente conseguida gracias al general Mola, quien envió a Roma a Luis Zunzunegui, Pedro Sainz Rodríguez y Antonio Goicoechea. Gracias a esta delegación monárquica el Duce se decidió a prestar ayuda a Franco ${ }^{15}$. Para otros historiadores dicha misión fue mucho más limitada que las gestiones que, a través del cónsul italiano en Tánger, estaba realizando Franco ${ }^{16}$. En opinión de Ismael Saz, se ha mitificado la visita a Ciano de los enviados del general Mola. La decisión del Duce de ayudar a Franco ya había sido tomada con anterioridad a su llegada a Roma el 28 de julio de $1936^{17}$.

En el período de tiempo que trascurrió desde el 18 de julio hasta el reconocimiento por parte de Italia del Gobierno rebelde, el 18 de noviembre de 1936, la situación de José María Aguinaga fue deteriorándose cada vez más, no solamente en relación con el Gobierno de Mussolini, sino también por falta de apoyo de las autoridades republicanas, hechos que le llevaron a presentar su dimisión el 28 de agosto de 1936.

Como ya hemos señalado, a finales de julio, la ayuda italiana a los rebeldes era un hecho irrefutable. Sin embargo, las relaciones diplomáticas entre España e Italia no habian sido rotas definitivamente. Ante esta situación no es de extrañar la falta de cooperación entre el Ministerio de Asuntos Exteriores italianos y el encargado de Negocios español. El 4 de agosto, el jefe de protocolo de dicho Ministerio tuvo que aceptar el nombramiento de Aguinaga como único representante del Gobierno español. Sin embargo, no entraba dentro de las disposiciones del Gobierno italiano indisponerse con el personal de la embajada española que había negado la entrada de Aguinaga en la cancillería, y se le sugirió que desistiese de

${ }^{13}$ Coverdale, J. F., I facisti italiani alla guerra di Spagna. Roma, Bari, Laterza, 1977.

${ }^{14}$ Coverdale, op. cit.

${ }^{15}$ Thomas, H., Histoire de la guerre d'Espagne, t. I. Paris, Robert Laffont, 1961, pág. 396. 1985

${ }^{16}$ VINAS, Ángel, La guerra civil española cincuenta años después. Barcelona, Labor,

${ }^{17}$ SAZ, Ismael, Italia y la guerra civil española. Madrid, CSIC, 1986. 
instalarse en dichos locales, pues el único modo de evacuarles seria por la fuerza, y en esas condiciones, el Gobierno italiano no estaba dispuesto a prestarle las fuerzas necesarias, hecho que expondría al Gobierno a un escándalo y a unas consecuencias que, en modo alguno, deseaba afrontar. Quedaba claro que el Gobierno italiano únicamente trataba de ganer tiempo hasta el reconocimiento oficial de las tropas sublevadas ${ }^{18}$.

Desprovisto de toda ayuda oficial para llevar a cabo su misión, Aguinaga se encontró en una situación delicada y solicitó el apoyo del representante francés en Roma, comunicándole su intención de abandonar inmediatamente el país, corriendo el riesgo de provocar la ruptura de relaciones diplomáticas entre España y el Gobierno italiano. El representante francés actuó como intermediario rogando, por un lado, a Aguinaga de no tomar una decisión definitiva, y por otro, haciendo gestiones de carácter no oficial ante el Conde Ciano para que le recibiese. Después de lograr la entrevista parece que los ánimos se calmaron momentáneamente. Aguinaga fue autorizado por el Gobierno republicano a tomarse unas cortas vacaciones hasta que su situación se hubiera aclarado definitivamente ${ }^{19}$.

A finales de agosto las relaciones diplomáticas entre España e Italia se encontraban en un callejón sin salida. El ministro de Estado español decidió retirar a Aguinaga de su puesto proponiéndole como salida las Embajadas de Varsovia o Bucarest. Aguinaga, que consideraba haber realizado una difícil misión en Italia, se sintió menospreciado por las autoridades republicanas y presentó su dimisión el 5 de septiembre de 1936. Sin embargo, junto a sus sentimientos personales no hay que olvidar el nuevo cambio que había realizado el Gobierno republicano con el nombramiento de Largo Caballero como presidente del Consejo. La mayoría de los diplomáticos españoles que habían permanecido fieles al Gobierno de la República el 18 de junio, cambiaron radicalmente de actitud a partir del mes de septiembre.

Aguinaga, que habia conseguido, gracias a las gestiones del embajador francés en España, M. Herbette, sacar a su esposa de San Sebastián, se refugió en San Juan de Luz y quiso entrar en la zona franquista alegando motivos familiares en una carta dirigida al ministro de Asuntos Exteriores de Franco el 3 de octubre de 1936, pero no se le permitió hacerlo. Ante tal situación el Gobierno de la República le separó de la

18 AMAE. RE. 163. Aguinaga a Barcia, 4-8-1936.

${ }^{19}$ AMAEF. Europe, 1930-1940. Espagne, V. 140. Chambrun a Delbos. Roma, 16-81936. 
carrera diplomática. No tuvo mejor suerte con el Gobierno de Franco. José María Aguinaga fue declarado «jubilado» en agosto de 1938 y tardaría nueve años en reintegrarse en la carrera diplomática.

La actitud del Vaticano no fue paralela a la del Gobierno italiano, manteniendo relaciones diplomáticas con el Gobierno republicano hasta los últimos meses de 1937, cuando monseñor Antoniutti fue enviado a Burgos con carácter no oficial. No obstante, hasta mayo de 1938 no se intercambiarian embajadores, monseñor Cicogani por parte de la Santa Sede, y José Yanguas Messias, por parte de Franco.

Luis de Zulueta había presentado sus credenciales a Pío XI el 9 de mayo de 1936. Antiguo seminarista, fue nombrado embajador ante la Santa Sede durante el Gobierno provisional en 1931, pero el Vaticano denegó el "placet" por tratarse de un discipulo de Francisco Giner ${ }^{20}$. Tanto el cardenal Vidal y Barraquer, arzobispo de Tarragona, como el Nuncio de Madrid, monseñor Tedeschini, apoyaron el nombramiento de Zulueta. Sin embargo, la negativa del Vaticano se fundamentaba en que nunca se habia aceptado un embajador que no fuese católico procedente de un país eminentemente católico ${ }^{21}$. Después de la ruptura con los radicales, Azaña necesitaba encontrar un nuevo ministro de Estado que no perteneciese a Acción Republicana, y ofreció la cartera de Estado a Luis de Zulueta ${ }^{22}$.

Al iniciarse la guerra civil, el embajador ante el Vaticano no sufrió inmediatamente los efectos de la guerra. Zulueta, en contestación a la Circular 23 del Ministerio de Estado, presentó su adhesión al Gobierno republicano el 22 de julio. Así lo hicieron también el ministro consejero, Ángel de la Mora y Arenas, el secretario José María Estrada y Aceval y el agregado Blay hasta el 14 de agosto, fecha en que presentaron su dimisión ante el Gobierno de la República y su adhesión a la Junta de Defensa ${ }^{23}$. En el caso de Ángel de la Mora, pese a su diferente ideologia política, Zulueta siempre manifestó su corrección en todo momento hacia su persona, así como sus muestras de afecto. Esta simpatía sería motivo para que el Tribunal de depuración de funcionarios diplomáticos franquista le reprochase no haber dimitido el 18 de julio. Posteriormente, en marzo de 1938, Ángel de la Mora pasó a prestar sus servicios al Ministerio de Asuntos Exteriores del Gobierno de Franco.

\footnotetext{
${ }^{20}$ Azañ, M., Memorias politicas y de guerra. Barcelona, Grijalbo, 1981, pág. 619.

AMAE. Despacho 110. Gómez Ocerín ministro de Estado, 3-6-1931.

22 AZAÑA, op. cit., pág. 552.

${ }^{23}$ AMAE. CRE. 163-164.
} 
A pesar que la situación de la embajada ante el Vaticano no sufrió los avatares que la bilateral en Roma, el Palacio de España tampoco se encontraba seguro. Zulueta tuvo que solicitar la intervención del representante francés, M. Chambrun, ante el cardenal secretario de Estado, monseñor Pacelli, para reforzar las medidas de seguridad por parte de las autoridades italianas ${ }^{24}$. Desde el inicio de la sublevación, el Vaticano mantuvo siempre una actitud neutral respecto al embajador Zulueta. Sin embargo, una serie de hechos extraños tuvieron lugar en el Palacio de España. Las claves de cifra de la embajada desaparecieron. Zulueta tenía a su servicio personal italiano pagado por los españoles que en Roma simpatizaban con los rebeldes. No obstante, el embajador español no tomó medidas contra ellos ${ }^{25}$. Ante tales circunstancias, el subsecretario del Ministerio de Estado republicano, Rafael Ureña, envió en septiembre de 1936 a Javier Conde García a fin de que ayudase a los trabajos de la embajada. Conde, que no era diplomático de carrera, había conseguido la confianza del Gobierno republicano, cuando en realidad actuaba como agente doble al servicio de Franco ${ }^{26}$.

La Iglesia, en particular la española, estuvo en su mayor parte en favor de los rebeldes. Sin embargo, el Vaticano, a través del cardenal Pacelli, había intentado que los dos bandos llegasen a un acuerdo. Por ello, pese a las presiones de los agentes franquistas en Roma, la Santa Sede mantuvo relaciones diplomáticas con la República aún después de la marcha del embajador Zulueta. En efecto, a finales de septiembre de 1936, Zulueta tomó la decisión de abandonar su puesto en Roma, hecho que causó gran sorpresa en el Vaticano y entre el cuerpo diplomático. Varias razones motivaron su decisión. Por un lado, el viaje del cardenal Pacelli a los Estados Unidos, una de las personas que mayor apoyo habian prestado a Zulueta contra las presiones de los rebeldes y de los mismos italianos partidarios del Gobierno de Burgos. Por otro, y éste es el hecho determinante de su marcha, el asunto de los cheques que le eran enviados desde Madrid y que no recibía, puesto que los fondos eran depositados en la cuenta del representante oficioso de Franco, el marqués de Magaz. El desánimo de Zulueta le llevó a aceptar la cíerta de este último de darle uno de los cheques retenidos para poder salir de

${ }_{24}$ AMAEF. Europe, 1930-1940. Espagne, V. 140. Chambrun a Delbos, 14-8-1936.

25 AMAEF. Europe, 1930-1940. Espagne, V. 140. Jacques Truelle, encargado de Negocios francés a ministro Delbos, 5-10-1936.

${ }_{26}^{26}$ ZULUETA, Carmen, "La guerra desde la embajada del Vaticano", en Historia 16, núm. 4. Madrid 1986. Después de la guerra, Conde sería uno de los ideólogos del franquismo y embajador en diferentes países. 
Roma con destino a Francia. El mismo Magaz sugirió a Zulueta que permitiese la entrada en la embajada a Ángel Mora para hacerse cargo de la misma.

En unas declaraciones de monseñor Tardini al encargado de Negocios francés, le comunicó que Zulueta le había visitado el 2 de octubre por la mañana para anunciarle su partida para París esa misma noche. En ningún momento Zulueta recriminó la actitud del Vaticano, bien al contrario, manifestó a monseñor Tardini su agradecimiento por los buenos oficios llevados a cabo por su parte. Sin embargo, la postura de Zulueta no era compartida por las autoridades del Vaticano decididas a no admitir al señor de la Mora, representante de un Gobierno no reconocido, en lugar del embajador acreditado oficialmente ante la Santa Sede, hasta el punto de mandar retirar la bandera del Gobierno de Burgos que ondeaba en el Palacio de España después de la marcha de Zulueta.

En opinión del encargado de Negocios francés, la actitud de Zulueta no fue correcta, aunque comprendiese la difícil situación y aislamiento en la que se encontraba. Por otro lado, las continuas protestas del Vaticano contra las persecuciones de religiosos en España habian llevado a Zulueta a utilizar sus buenos contactos con las autoridades de la Santa Sede para seguir manteniendo las relaciones diplomáticas, pues en su opinión, una ruptura podría acarrear consecuencias peligrosas.

La misión de Zulueta en Roma, pese a su dimisión, fue plenamente reconocida por el Vaticano. Según palabras de monseñor Tardini, el embajador de España era cel más simpático de todos los anticlericales que había conocido". Como muchos diplomáticos españoles, Zulueta se dio cuenta que la situación de España no permitia a un intelectual, filósofo animado de liberalismo como él, servirla como hubiese sido necesario ${ }^{27}$.

El Vaticano siguió manteniendo relaciones con Zulueta como embajador de la República hasta finales de 1936, fecha en que'se trasladó a Bogotá donde fue profesor de la Escuela Normal, y posteriormente en los Estados Unidos ${ }^{28}$.

Archivos consultados ${ }^{29}$.

27 AMAEF. Europe, 1930-1940. Espagne, V. 140.

${ }^{28}$ RuBı, Manuel, Diccionario de la guerra civil española, t. II. Barcelona, Planeta, 1987, pág. 798.

${ }_{29}$ AMAE: Archivos Ministerio Asuntos Exteriores. Madrid.

AMAEF: Archivos Ministerio Asuntos Exteriores Francés. Paris.

FN: Fondo Navasqües. 